\title{
3 Research Suare \\ Sox10 Gene is Required for the Survival of Saccular and Utricular Hair Cells
}

Jing-cui Qi

Peking University

Qing-qing Jiang

Chinese PLA General Hospital

Long Ma

PLA Rocket Force Characteristic Medical Center

Shuo-long Yuan

Chinese PLA General Hospital

Wei Sun

the State University of New York at Buffalo

Li-sheng Yu

Peking University

Wei-wei Guo

Chinese PLA General Hospital

Shi-ming Yang ( $\nabla$ shm_yang@163.com )

Chinese PLA General Hospital https://orcid.org/0000-0002-7808-2566

\section{Research Article}

Keywords: Sox10, Waardenburg Syndrome, Saccule, Utricle, Miniature porcine model

Posted Date: June 11th, 2021

DOI: https://doi.org/10.21203/rs.3.rs-549350/v1

License: (c) (1) This work is licensed under a Creative Commons Attribution 4.0 International License.

Read Full License 


\section{Abstract}

Background:. Pathological changes of the cochlea and hearing loss have been well addressed in Waardenburg syndrome (WS). However, the vestibular organ malformation in WS is still largely unknown. In this study, the differentiation and development of vestibular sensory epithelium and vestibular function caused by SOX10 mutation, a critical gene induces WS, has been studied in minature pig model.

Results: Degeneration of vestibular hair cells was found in this Sox10 mutation porcine model. Inner ear phenotype of the SOX10/R109W miniature pigs showed cochlear abnormalities as well as saccular hypofunction. In the mutant pigs, no prominent dissimilarity was shown in the bone structure of the semicircular canals. However, the saccular membrane was collapsed and the infusion of stereocilia of the hair cells were observed. There was no dark cells in the uticules in th mutant pigs. The density of the utricular hair cells was also significantly lower in the mutant pigs compared to the wild type.

Conclusions: Our study demonstrated that the S0X10 gene and melanocytes play important roles in the vestibular organ development. Sox10 mutation disrupts the KIT-DCT signaling pathway, affects the development of melanocytes and leads to vestibule morphogenesis.

\section{Introduction}

Maintaining body balance relies on the vestibular, visual, body somatosensory inputs and central nervous system (Clarke, 2010; Iwasaki and Yamasoba, 2015; Marioni et al., 2013). The vestibular organ plays an important role in the balancing system and is considered as one of the important organ in maintaining upright posture in human (Gu et al., n.d.). The vestibular signals have been shown to contribute to higher cognitive functions such as navigation. Sensorineural hearing loss and balance dysfunction are common human diseases. These diseases can seriously affect the quality of life and bring a heavy burden to individuals, families and society.

The vestibular end organs, located in the inner ear, which has the same origin as cochlea, sense rotational and linear acceleration of head and its position relative to the gravitational field of earth (Khan and Chang, 2013). Vestibular end organ cells have vestibular hair cells and supporting cells, and hair cells can be divided into type I and type II cells (Eatock and Songer, 2011), damage of vestibular hair cells is irreversible (Meyers and Corwin, 2008a). Congenital hereditary diseases of the inner ear often affect vestibular structure and functions. A clinical study on vertigo and balance disorders in children showed that the inner ear malformation caused by Mondini deformity played an important role in causing vestibular dysfunctions. Vestibular impairment in children with sensori neural hearing hearing loss can lead to delays in posturo-motor control acquisition (Wiener-Vacher, 2008). Waardenburg syndrome (WS) is a common type of neural crest lesions, accounting for $2 \%-5 \%$ of congenital hereditary diseases of the inner ear. WS is an autosomal dominant genetic syndrome characterized by abnormal pigmentation of hair, skin, iris and sensorineural hearing loss. Mutations in the gene encoding SOX10 cause WS type II (WS2, OMIM \#611584) and type IV (WS4, OMIM \#613266), with the highest probability of vestibular 
organ malformation(Chen et al., 2016; Elmaleh-Bergès et al., 2012; Fernández et al., 2014; Kaya et al., 2017; Pingault et al., 2015, 2010; Song et al., 2016; Xu et al., 2016).

In the study of vestibular system, experimental animals play an irreplaceable role(Straka et al., 2016). In recent years, the miniature pig model has been more applied to the study of hereditary deafness(Guo et al., 2017; Yi et al., 2016, n.d.). At present, the research on congenital hereditary inner ear diseases mainly focuses on the pathological changes of the cochlea and very few studies on the vestibular system have been reported. Our previous work had reported a missense mutation (c.325A > T) of SOX10 in the minipig model, which was the ideal animal for Waardenburg syndrome (Hai et al., 2017; Hao et al., 2018; Zhou et al., 2016).. In this study, we use this model to study the pathological morphological changes of the peripheral vestibular organs induced by Sox10 mutation and to explore the role of Sox10 gene in the development of vestibular organs.

\section{Materials And Methods}

\section{Animals}

Sox10 missense mutant(c.325A>T) Bama-minipigs were described previously (Hai et al., 2017)(Hao et al., 2018).All experiments involving animals or embryos were performed by guidelines of the Institutional Animal Care and Use Committee at the Third Military Medical University and Chinese PLA Medical School.

\section{Auditory Brainstem Response (ABR) tests}

Miniature pigs were anesthetized with xylazine $(0.1 \mathrm{mg} / \mathrm{kg}$, i.m.) and ketamine ( $15 \mathrm{mg} / \mathrm{kg}$, i.m.) prior to auditory brainstem response (ABR). Smart-EP software (Intelligent Hearing System, Miami, USA) was used to test the ABR and cVEMP. For ABR recording, four needle electrodes were inserted into the skin of both pinnas, the base of the tail and vertex, sound stimuli earphone at the testing ear. ABR was evoked with click stimuli. The repetition rate was $12.1 / \mathrm{s}$, and 1250 sweeps were averaged.

Miniature pigs were laid on baoding hammock without anesthesia to test cervical vestibular evoked myogenic potential(cVEMP). cVEMP was recorded in miniature pigs by using methods established in guinea pigs(Yang and Young, 2005), insteading of fixing pigs' heads, we used feeding stimulation to keep heads elevated and neck hyperextended during recording, each pig was trained many times before the test. Two needle electrodes were placed into the skin of the base of the tail for grounding and vertex for reference, two needle electrodes were inserted into both neck extensor muscles (Corneil and Camp, 2018), and electromyography (EMG) was monitored throughout the test. Acoustic stimuli consisted of tone-burst at $1 \mathrm{kHz}$, the EMG signal was amplified with a band-pass filter between 10 and $1000 \mathrm{~Hz}$. 40 sweeps were averaged for each run. All miniature pigs underwent a serial cVEMP testing, starting with the $130 \mathrm{~dB}$ sound pressure level (SPL) and then lowering the $10 \mathrm{~dB}$ step until there were no waveforms, so the threshold was determined. 


\section{Immunofluorescence Phalloidin staining of vestibular hair cells and hair cell quantification}

Miniature pigs of postnatal 1 day were euthanized by urethane $(1.5 \mathrm{~g} / \mathrm{Kg}$, i.m. $) / \mathrm{CO}_{2}$ gas overdose, temporal bones were obtained and fixed immediately in $4 \%$ paraformaldehyde at $4{ }^{\circ} \mathrm{C}$ overnight. The vestibular sensory epithelia were subsequently micro-dissected in $0.1 \mathrm{M}$ phosphate buffer, then permeabilized in 1\% Triton X-100 in PBS for 30 min. F-actins to visualize stereocilia bundles and cell nuclei were stained by Alexa Fluor 555-Phalloidin (1:1000 dilution in PBS, 1h, room temperature. Sigma, 1:800) and DAPI (Invitrogen D3571, 1:1000) respectively.

\section{Counting and data analysis}

For confocal microscopy analysis, we used Zess 880 Confocal Microscope (Olympus, Center Valley, PA). Photographs taken with these microscopes were cropped and labeled with Adobe Photoshop and Illustrator software (Adobe System, San Jose, CA). For each utricle, three areas $(36.9 \mu \mathrm{m} \times 36.9 \mu \mathrm{m})$ each of the striolar and extrastriolar regions were imaged and averaged as one data point for each region (striola and extrastriola).

\section{Scanning electron microscopy (SEM)}

Miniature pigs of postnatal 1 day and embryos at E75 were euthanized, and inner ears were harvested as described above. Tissues were fixed with $2.5 \%$ glutaraldehyde in $0.1 \mathrm{M} \mathrm{PB}$ at $4{ }^{\circ} \mathrm{C}$ overnight. The vestibular sensory epithelia were collected. They were treated with $1 \%$ osmium in $0.1 \mathrm{M} \mathrm{PB}$ for $1 \mathrm{~h}$, after dehydration via an ethanol gradient of increasing concentrations, they were dehydrated within a critical point dryer. then mounted on aluminum stubs and coated with $10 \mathrm{~nm}$ gold layer, and viewed under a scanning electron microscope.

Vestibular end organ were fixed with $2.5 \%$ (vol/vol) glutaraldehyde with Phosphate Buffer (PB) $(0.1 \mathrm{M}, \mathrm{pH}$ 7.4), washed four times in PB. Then were first immersed in 1\% (wt/vol) OsO4 and 1.5\% (wt/vol) potassium ferricyanide aqueous solution at $4{ }^{\circ} \mathrm{C}$ for $1 \mathrm{~h}$. After washing, the tissues were incubated in filtered 1\% thiocarbohydrazide aqueous solution (Sigma-Aldrich) at room temperature for $30 \mathrm{~min}, 1 \%$ unbuffered $0 \mathrm{sO} 4$ aqueous solution at $4{ }^{\circ} \mathrm{C}$ for $1 \mathrm{~h}$ and $1 \%$ UA aqueous solution at $4{ }^{\circ} \mathrm{C}$ overnight following four rinses in ddH2O for 5 min each between each step. Then were dehydrated through graded alcohol $(30,50,70,80,90,100 \%, 100 \%, 5 \mathrm{~min}$ each $)$ into pure acetone $(2 \times 5 \mathrm{~min})$. Samples were infiltrated in a graded mixtures $(3: 1,1: 1,1: 3)$ of acetone and SPI-PON812 resin (19.6 ml SPI-PON812, 6.6ml DDSA and 13.8ml NMA), then changed pure resin. Finally, samples were embedded in pure resin with $1.5 \%$ BDMA and polymerized for $12 \mathrm{~h}$ at $45^{\circ} \mathrm{C}, 48 \mathrm{~h}$ at $60^{\circ} \mathrm{C}$. The ultrathin sections ( $70 \mathrm{~nm}$ thick) were sectioned with microtome (Leica EM UC6), and imaged by a Scanning Electron Microscope (FEI Helios Nanolab 600i dual-beam SEM) with its an immersion high magnification mode (CBS detector, $2 \mathrm{kV}, 0.34 \mathrm{nA}$ ).

\section{Micro-CT scanning}


In order to assess the 3D structure and integrity of the inner ear, samples from WT and heterozygous pigs at postnatal day 1 were fixed with $4 \%$ paraformaldehyde and scanned by a micro-CT system (Quantum GX, Perkin Elmer) using the following parameters: 90 kV, 160 mA, 24 mm of field of view, and time 4.5 min. The structure of the inner ear was analyzed and reconstructed using IMARIS 9 (Bitplane, AG) software.

\section{RNA Isolation From Vestibular Tissue}

Vestibular end organs were obtained from 3 wild-type and 3 mutant embryos at E75, respectively. Total RNA was extracted using the Total RNA Extractor冈Trizol『kit (B511311, Sangon, China) according to the manufacturer's protocol, and treated with RNase-free DNase I to remove genomic DNA contamination. RNA integrity was evaluated with a $1.0 \%$ agarose gel. Thereafter, the quality and quantity of RNA were assessed using a NanoPhotometer ${ }^{\circledR}$ spectrophotometer (IMPLEN, CA, USA) and an Agilent 2100 Bioanalyzer (Agilent Technologies, CA, USA). The high quality RNA samples were subsequently submitted to the Sangon Biotech (Shanghai) Co., Ltd. for library preparation and sequencing.

\section{Library Construction and Sequencing}

The VAHTSTM mRNA-seq V2 Library Prep Kit for Illumina was used for the RNA-seq library preparation, PCR products were purified (AMPure XP system) and library quality was assessed on the Agilent Bioanalyzer 2100 system. The libraries were then quantified and pooled. Paired-end sequencing of the library was performed on the HiSeq XTen sequencers (Illumina, San Diego, CA).

\section{Data assessment and quality control}

FastQC (version 0.11.2) was used for evaluating the quality of sequenced data. Raw reads were filtered by Trimmomatic (version 0.36 ). And the remaining clean data was used for further analysis.

Alignment with reference genome

Clean reads were mapped to the reference genome by HISAT2 (version 2.0) with default parameters. RSeQC (version 2.6.1) was used to statistics the alignment results. The homogeneity distribution and the genome structure were checked by Qualimap (version 2.2.1). BEDTools (version 2.26.0) was used to statistical analysis the gene coverage ratio.

\section{Expression analysis}

Gene expression values of the transcripts were computed by StringTie (version 1.3.3b). Principal Component Analysis (PCA) and Principal co-ordinates analysis (PCoA) were performed to reflect the distance and difference between samples. The TPM (Transcripts Per Million), eliminates the influence of gene lengths and sequencing discrepancies to enable direct comparison of gene expression between samples. DESeq2 (version 1.12.4) was used to determine differentially expressed genes (DEGs) between two samples. Genes were considered as significant differentially expressed if q-value $<0.001$ and 
|FoldChange| $>2$. When the normalized expression of a gene was zero between two samples, its expression value was adjusted to 0.01 (as 0 cannot be plotted on a log plot). If the normalized expression of a certain gene in two libraries was all lower than 1, further differential expression analysis was conducted without this gene. Gene expression differences were visualized by scatter plot, MA plot and volcano plot.

Gene Ontology (GO) and Pathway Enrichment Analysis of DEGs

Functional enrichment analyses including Gene Ontology (GO) and KEGG was performed to identify which DEGs were significantly enriched in GO terms or metabolic pathways. Gene Ontology (GO) is an international standard classification system for gene function. DEGs are mapped to the GO terms (biological functions) in the database, the number of genes in every term is calculated, and a hypergeometric test is performed to identify significantly enriched GO terms in the gene list out of the background of the reference gene list. The Kyoto Encyclopedia of Genes and Genomes (KEGG) database is a public database of pathway data, KEGG pathway analysis identifies significantly enriched metabolic pathways or signal transduction pathways enriched in DEGs compared to a reference gene background, using the hypergeometric test. GO terms and KEGG pathway with false discovery rate (q-value) $<0.05$ were considered as significantly altered.

\section{Real-time PCR (RT-PCR)}

Total RNA was extracted from vestibular end organs using TRIzol reagent (Invitrogen, USA). Random hexamers were used for synthesizing the first cDNA strand synthesis with $1 \mu \mathrm{g}$ of total RNA (Molecular Biology). The thermal cycling profile was $95^{\circ} \mathrm{C}$ for $30 \mathrm{~s}$, followed by 40 cycles of $95^{\circ} \mathrm{C}$ for $5 \mathrm{~s}, 58^{\circ} \mathrm{C}$ for $10 \mathrm{~s}$, and extension at $95^{\circ} \mathrm{C}$ for $5 \mathrm{~s}, 65^{\circ} \mathrm{C}$ to $95^{\circ} \mathrm{C}$, and $0.5^{\circ} \mathrm{C}$ for $5 \mathrm{~s}$. The PCR primers are listed in Table 1. The expression of each target gene in WT and mutant littermates was standardized against that of actin mRNA using the $2^{-\Delta \Delta \mathrm{Ct}}$ method.

\section{Western blot analysis}

Vestibular end organs were obtained from 3 wild-type and 6 mutant embryos at E75, respectively. The proteins were separated using $10 \%$ sodium dodecyl sulfate-polyacrylamide gel electrophoresis (SDSPAGE) and transferred onto PVDF membranes(Bio-Rad, CA). After three 5-min washes in TBST (Trisbuffered-saline with Tween). The membranes were blocked overnight in TBST containing 5\% dried milk for $1 \mathrm{~h}$ at room temperature, and then were incubated overnight at $4^{\circ} \mathrm{C}$ with either SOX-10 anti- body (1:100 dilution in blocking buffer) (sc-365692, Santa) or Anti-S100 antibody (1:2500 dilution in blocking buffer) (ab52642, Abcam) or Anti-TRP2/DCT antibody (1:1000 dilution in blocking buffer) (ab74073, Abcam). The membranes were then washed three times for 5 min each in TBST and incubated for $1 \mathrm{~h}$ with the secondary antibody (1:4000 dilution )(Zhongshan Golden Bridge Biotechnology Co.Ltd. China) at room temperature. The membranes were washed three times for 10 min withTBST. and then visualized with the Super ECL Plus Detection Reagent (Applygen, China). The membranes were wrapped in plastic wrap then exposed to X-ray film. 


\section{Results}

\section{Profound sensorineural hearing loss and inner ear malformations in SOX10+R109W miniature porcine model}

The miniature porcine model exhibited WS2-like phenotypes, was well-studied for depigmentation of head, ears, hip and retin iridis (Figure 1A). ABR tests of both the wide type and albino minipigs were performed. In the wide type the ABR threshold was $40.75 \pm 1.105(\mathrm{~N}=20) \mathrm{dB} S \mathrm{SPL}$ with the stimulus of click, and ABR waveforms were absent up to stimulus intensities of $120 \mathrm{~dB}$ SPL in the mutation miniature pigs (Figure 1B), which was consistent with previous studies (Hao et al., 2018). Inner ear phenotype of the SOX $10^{+/ R 109 W}$ miniature pigs showed cochlear abnormalities(Figure $1 \mathrm{C}$ ) as well as saccular hypofunction (Figure 1D). The cochlea of the wild-type minipigs had elongated to 3.5 turns while the mutation only reached 1.5 turns(Figure $1 \mathrm{C}$ ). No prominent dissimilarity was shown in whole spatial structures of vestibule and semicircular canals.collapsed saccule wall membrane was found in the vestibular cavity without covering periotic bone (Figure 1D).

\section{Vestibular dysfunction in SOX10+/R109W miniature porcine model}

To determine the impairments of vestibular function in SOX10+/R109W miniature pigs, we conducted an cervical vestibular evoked myogenic potential(cVEMP) in the SOX10 $10^{+/ R 109 \mathrm{~W}}$ and wild-type minipigs at postnatal day 90 (P90) (Figure 2). In the wild-type miniature pigs, the latency of peak(N1) of cVEMP recorded from the neck extensor muscles was $9.92 \pm 0.74 \mathrm{~ms}$, with an average amplitude of $59.20 \pm 21.22$ $\mu \mathrm{V}$ (Figure $2 \mathrm{C}, \mathrm{D})$. The response rate was $83 \%$ at stimulus intensity of $130 \mathrm{~dB}$ SPL, while no response was found on the mutant pigs(Figure 2B).

\section{Sox10 Mutation caused developmental disorders of the saccule and the utricle}

To investigate the pathology of vestibular dysfunction, we microdissected vestibular end organ and immunostained saccular macula for the stereocilia marker Phalloidin-TRITC. Saccular hair cells in the wild-type minipigs at postnatal day 1 were well developed and regularly arranged, which was a narrow striola separating two broader, extrastriolar regions. Saccular macula had a question-mark shape which

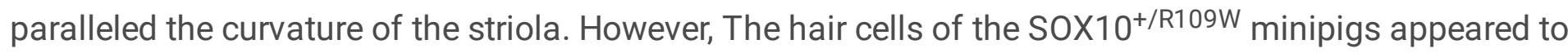
be severely degenerated, no stereocilia were visible on the cuticular plates(Figure 3A). In order to obtain more information about the effects of Sox10 on the development of saccule, we observed the ultrathin sections of saccular macula and imaged by SEM with immersion high magnification mode(Figure 4A). In addition to the loss of hair cells of saccular macula, the saccular wall collapsed and saccular roof epithelium disappeared in mutant pigs. The results showed that the saccular sensory epithelium was extremely seriously damaged at birth.

Utricular size and density of utricular hair cells changed in SOX10+R109W miniature pigs. PhalloidinTRITC staining showed that utricular hair cells in the wild-type minipigs at postnatal day 1 were well developed and regularly arranged, which was a narrow striola separating two broader, extrastriolar 
regions. Utricular macula had a shell-mark shape which paralleled the curvature of the striola(Figure 3B). In contrast to the wild-type minipigs, the overall size of whole sensory epithelium reduced(Figure 3B,m; $t=5.02, P=0.0007$, Unpaired $t$ test) in SOX10 $1 /$ R109W miniature pigs. We quantified the number of hair cells in striola and extrastriolar regions, hair cell density in extrastriolar reduced due to Sox10 mutation(Figure 3B, $n ; t=4.92, P=0.0008$, Unpaired $t$ test). Hair cell density in striolar did not change in SOX10 $10^{+/ R 109 W}$ miniature pigs, while stereocilia bundle arranged disorderly in SOX10+/R109W miniature pigs(Figure 3B,i). Utricular macula had a shell-mark shape, hair cells in the wild-type and mutant minipigs were well developed, utricular macula hair cell orientation was perpendicular to the reversal line (Figure 4B1). The melanocytes in the membrane tissue around the utricular macula were missing, and some of the dark cells were abnormal (Figure 4B2) in SOX10+/R109W miniature pigs.Scanning electron microscopy combined with Phalloidin-labeled utricular hair cells under confocal observations, the sensory epithelial area and the hair cell density of extrastriolar regions of the SOX10+/R109W miniature pigs was reduced .Based on this, it was speculated that the possible mechanism was that the Sox 10 gene mutation causes melanin abnormal, affectting the lymphatic circulation in the utricle, leading to secondary changes in the hair cells of the utricle.

A schematic figure of saccule and utricle disorders in SOX10 ${ }^{+/ R 109 W}$ miniature pigs (Figure 4C).Saccule wall membrane collapsed and the hair cells in the mutant saccule shed off completely. Dark cells were disappeared in the mutant utricle.

\section{The profiling of transcriptome from wild-type and mutated vestibular.}

To elucidate the mechanism of vestibular dysfunction in Sox10 mutated pigs, a profiling of vestibular transcriptome has been done in Sox10 mutated pigs and WT pigs. The principal component analysis (PCA) showed the six samples divided into two clusters, in which 3 vestibular samples from Sox 10 mutated pigs were clustering in the same group labeled by red circle, and the other 3 WT- vestibular samples were also clustering together labeled by blue circle (Fig 5A). Volcano plot (Fig 5B) and heat map (Fig 5C) showing some of down regulated genes were detected in Sox10 mutated pigs vestibular comparing to WT samples. Furthermore $\mathrm{GO}$ analysis revealed all above different expression genes were enriched in melanosome and pigment granule (Fig 5D). Moreover KEGG enrichment analysis also indicted the Melanogenesis and Tyrosine metabolism signaling pathway are mainly involved in SOX10 related vestibular dysfunction (Fig 5E). Considering the Tyrosine is a crucial material in melanogenesis, it indicated that the dysfunction of pigment synthesis may be a reason for loss of hair cell in saccular and uticular related Sox10 mutation. Together, a fully melanogenesis diagram from KEGG were showed in Fig $5 \mathrm{~F}$, and the $\mathrm{DCT}$, one of a down-regulated gene in SOX10 mutated pig, was showed as a crucial factor in melanosome and involved in survival of saccular and uticular hair cells.

\section{Sox10 mutation disrupts the KIT-DCT signaling pathway in Sox10 mutated pigs}

Compared with the wild type, part of the mutant saccule were fused, and the hair cells were missing at E75, saccule hair cells were fused and missing severely, and the epithelial damage was gradually 
aggravated(Figure6A); Melanocytes was missing in utricle wall, hair cells had no obvious abnormalities(Figure6A). Quantitative RT-PCR (Figure6B) and Western blot (Figure6C) revealed the downregulation of SOX10-regulated genes DCT, not affect MITF. Finally, SOX10-regulated KIT-DCT signaling pathway was impaired, leading to vestibule morphogenesis(Figure6D).

\section{Discussion}

In this study, we studied on vestibular function and pathological changes of the vestibular end organ in

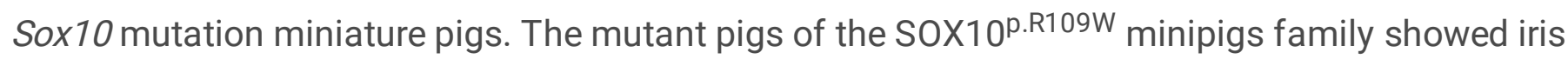
heterochromia, extremely severe sensorineural hearing loss, and abnormal vestibular function. We also detected that severe damage in the saccules and mild damage in the utricles.

SOX10 was widely expressed in human fetal and adult tissues and plays an extremely important role in human development and physiology(Bondurand et al., 1998; Pusch et al., 1998; Watanabe et al., 2000). SOX10 is the main pathogenic gene causing WS. Our findings indicates that WS does not only cause hearing loss, but also affects the vestibular organs.

Our animal model had great advantages in studying vestibular function. The model could meet the conditions for testing at a awake state. cVEMP were used to detect the saccule function and inferior vestibular nerve pathways in miniature pigs, and no cVEMP response was detected in the SOX10 10 R $109 \mathrm{~W}$ porcine model, indicating impaired function of saccule. Unfortunately, we were not able to detect oVEMP, and it is necessary to explore the suitable detection test methods in further experiments.

Our results showed that the saccule hair cells and cyst wall of the mutant individuals were seriously damaged, and this occurred during embryonic development. During the development of the vestibular organs, there was no obvious general morphological abnormalities such as enlargement of the vestibular cistern and absence of semicircular canals. These results indicated that Sox10 gene played an important role in the development and maintenance the structure and function of saccule. Utricular macular epithelium comprised supporting cells and sensory hair cells. The utricular roof epithelium was composed of dark cells (DCs) and melanocytes (MCs)(A et al., n.d.). The function of dark cells was to secrete and absorb endolymph, and the utricle could secrete and absorb endolymph by itself. The dark cells and melanocytes played an important role in maintaining endolymph circulation(Nicolas et al., 2001; Palma et al., 2018; Young, 2018). The endolymph was derived from the cochlea and transported to the endolymphatic sac, where it is reabsorbed. Due to missing of the dark cells in saccule wall, the mutant animals could not produce and absorb endolymphs in saccules. It was known that damage of vestibular hair cells during development is irreversible(Matsui and Ryals, n.d.; Meyers and Corwin, 2008b; Tribukait et al., 2005). Scanning electron microscopy was used to observe the effect of Sox 10 mutation on the development of utricle, we found Sox10 mutation leaded to reduction of the area size and hair cell density of extrastriolar regions, hair cells arrangement of trastriolar regions was disordered. At the same time, the lack of melanocytes in the wall of the utricle and the abnormal morphology of the vestibular dark cells 
were observed. Due to the Sox10 gene mutation, the number of melanocytes reduced, or the migration of melanocytes affected, so that the number of melanocytes migrating to the utricle wall reduced.

Cochleosaccular degeneration occured in human and animal models, causing hyperpigmentation and hereditary deafness(Coppens et al., n.d.; Deol, 1970a, 1970b; Mair, 1976; Mair and Elverland, n.d.; Sampaio et al., n.d.; Strain, 2015; Sugiura and Hilding, n.d.). Related pathogenic genes including Mitf, Pmel, Kit, Ednrb, Tyrand Trpm1, and the specific mechanism was not yet clear. Melanocyte were missing in the mutant and the morphology of the vestibular dark cells was abnormal, compared to the influence of the saccule, the utricle wall did not collapse and the hair cells were not severely missing. So, if the Sox10 mutation affected the cochlear endolymphatic circulatory disorder, the utricle, which had the same secretion and absorption of endolymph as the cochlea, did not have the same serious pathological changes. our study found this pathological phenomenon, and exploring the mechanism was difficult, needing further study.

The results from high-throughput RNA-seq assay for vestibular tissues of the E75 porcine model showed that Dopachrome tautomerase $D c t$ ) was significantly down-regulated in mutant individuals. DCT was a key enzyme responsible for the synthesis of melanin. It was the target gene of SOX10 and MITF. It played an important role in the differentiation and development of melanocytes. Our study found that Sox10 mutation can directly affect the expression of Dct and directly impaired the development of melanocytes.. Our results also suggests thatmelanocytes played an important role in the development of the vestibular organs.

Our study results also indicated that Sox 10 mutation can disrupt the KIT-DCT signaling pathway and reduced mirgration melanocytes and. Therefore, the number of melanocytes migrating to the stria vascularis was reduced. This can cause the cochlea Endolymph circulatory disorder and affects the longitudinal flow and circulation of cochlear endolymph fluid. This may be the cause of pathological changes in the saccule wall and hair cells.

As vestibular symptoms can be compensated by the central nervous system, (Lacour et al., n.d.), identifying the potential vestibular lesions in patients with hereditary diseases can be challenging. Our animal model could help to identify vestibular dysfunction in WS and interpret clinical disorders .

\section{Declarations}

\section{Acknowledgements}

We are grateful to Xixia. Li, Xueke Tan囚for helping with sample preparation and taking SEM images at the Center for Biological Imaging (CBI), Institute of Biophysics, Chinese Academy of Science.

\section{Authors Contributions}

All authors contributed to the study conception and design. Material preparation, data collection and analysis were performed by Jing-cui Qi and Qing-qing Jiang. Shuo-long Yuan and Long Ma made a 
contribution in morphology. The first draft of the manuscript was written by Wei-wei Guo and Wei Sun and edited by Li-sheng Yu and Shi-ming Yang. All authors read and approved the final manuscript.

\section{Ethical approval}

All procedures performed in this study involving animals were approved and carried in accordance with the ethical standards of the Ethics Committee of Chinese PLA General Hospital. All efforts were made to minimize animal suffering, reduce the number of animals used, and utilize alternatives to in vivo techniques, when available.

\section{Consent for Participate}

Not applicable since this study does not involve research on human subjects.

\section{Consent for Publication}

Not applicable since this study does not involve research on human subjects.

\section{Availability of data and materials}

The datasets that support the findings of this study are available from the corresponding author upon reasonable request.

\section{Competing Interests}

None of the authors have any competing interests.

\section{Funding}

Financial funds: This work was supported by grants from the National Natural Science Foundation of China (NSFC \#81970897,82000981)

\section{References}

1. Junhui Jeong A, A BJYK, Jinsei Jung HH,CPW,DDCM,A, E, J.Y.C.A., E, S.H.K.A., n.d. P2RX2 and P2RX4 receptors mediate cation absorption in transitional cells and supporting cells of the utricular macula. Hearing Research 386

2. Bondurand N, Kobetz A, Pingault V, Lemort N, Encha-Razavi F, Couly G, Goerich DE, Wegner M, Abitbol M, Goossens M (1998) Expression of the SOX10 gene during human development. FEBS Lett 432:168-172. https://doi.org/10.1016/S0014-5793(98)00843-6

3. Chen $L$ (2016) A de novo silencer causes elimination of MITF-M expression and profound hearing loss in pigs 15

4. Chen Y, Yang F, Zheng H, Zhou J, Zhu G, Hu P, Wu W (2016) Clinical and genetic investigation of families with type II Waardenburg syndrome. Mol Med Rep 13:1983-1988. 
https://doi.org/10.3892/mmr.2016.4774

5. Clarke AH (2010) Laboratory testing of the vestibular system. Current Opinion in Otolaryngology Head Neck Surgery 18:425

6. Coppens AG, Résibois A, Poncelet L, n.d. Bilateral Deafness in a Maltese Terrier and a Great Pyrenean Puppy: Inner Ear Morphology 122, 223-228

7. Corneil BD, Camp AJ (2018) Animal Models of Vestibular Evoked Myogenic Potentials: The Past, Present, and Future. Frontiers in Neurology 9. https://doi.org/10.3389/fneur.2018.00489

8. Deol MS (1970a) The origin of the acoustic ganglion and effects of the gene dominant spotting (Wv) in the mouse. Journal of Embryology Experimental Morphology 23:773-784

9. Deol MS (1970b) The Relationship Between Abnormalities of Pigmentation and of the Inner Ear. Proceedings of the Royal Society of London 175, 201-217

10. Eatock RA, Songer JE (2011) Vestibular Hair Cells and Afferents: Two Channels for Head Motion Signals. Annu Rev Neurosci 34:501-534. https://doi.org/10.1146/annurev-neuro-061010-113710

11. Elmaleh-Bergès M, Baumann C, Noël-Pétroff N, Sekkal A, Pingault V (2012) Spectrum of Temporal Bone Abnormalities in Patients with Waardenburg Syndrome and SOX10 Mutations. American Journal of Neuroradiology 34:1257-1263

12. Fernández RM, Núñez-Ramos R, Enguix-Riego MV, Román-Rodríguez FJ, Borrego S (2014) Waardenburg Syndrome Type 4: Report of Two New Cases Caused by SOX10 Mutations in Spain. American Journal of Medical Genetics Part A 164

13. Gu Y, DeAngelis GC, Angelaki DE, n.d. A functional link between area MSTd and heading perception based on vestibular signals. Nature Neuroscience 10, 1038-1047

14. Guo W, Yi H, Yan Z, Ren L, Chen L, Zhao LD, Ning Y, He DZZ, Yang S-M (2017) The morphological and functional development of the stria vascularis in miniature pigs. Reproduction Fertility Development 29:585. https://doi.org/10.1071/RD15183

15. Hai T, Cao C, Shang H, Guo W, Mu Y, Yang, Shulin, Zhang, Ying, Zheng Q, Zhang T, Wang, Xianlong, Liu Y, Kong Q, Li K, Wang D, Qi M, Hong Q, Zhang R, Wang X, Jia Q, Wang X, Qin G, Li Y, Luo A, Jin W, Yao J, Huang J, Zhang H, Li M, Xie X, Zheng X, Guo K, Wang Q, Zhang S, Li L, Xie F, Zhang Yu, Weng $X$, Yin Z, Hu K, Cong Y, Zheng P, Zou H, Xin L, Xia J, Ruan J, Li H, Zhao W, Yuan J, Liu, Zizhan, Gu W, Li M, Wang Y, Wang H, Yang, Shiming, Liu, Zhonghua, Wei H, Zhao J, Zhou Q, Meng A (2017) Pilot study of large-scale production of mutant pigs by ENU mutagenesis. eLife 6. https://doi.org/10.7554/eLife.26248

16. Hao Q-Q, Li L, Chen W, Jiang Q-Q, Ji F, Sun W, Wei H, Guo W-W, Yang S-M (2018) Key Genes and Pathways Associated With Inner Ear Malformation in SOX10 p.R109W Mutation Pigs. Frontiers in Molecular Neuroscience 11. https://doi.org/10.3389/fnmol.2018.00181

17. Iwasaki S, Yamasoba T (2015) Dizziness and Imbalance in the Elderly: Age-related Decline in the Vestibular System. Aging Disease 6:38. https://doi.org/10.14336/AD.2014.0128

18. Kaya S, Hızlı Ö, Kaya FK, Monsanto RD, Paparella MM, Cureoglu S (2017) Peripheral vestibular pathology in Mondini dysplasia: Vestibular Hair Cells in Mondini Dysplasia. Laryngoscope 127:206- 
209. https://doi.org/10.1002/lary.25995

19. Khan S, Chang R (2013) Anatomy of the vestibular system: A review. Neurorehabilitation 32:437-443

20. Lacour M, Helmchen C, Vidal P-P, n.d. Vestibular compensation: the neuro-otologist's best friend. Journal of Neurology 263, 54-64

21. Mair IWS (1976) Hereditary deafness in the Dalmatian dog. Archives of Oto-Rhino-Laryngology $212: 1-14$

22. Mair IWS, Elverland HH, n.d. Hereditary deafness in the cat. An electron microscopic study of the stria vascularis and Reissner\"s membrane. Archives of Oto-Rhino-Laryngology 217, 199-217

23. Marioni G, Fermo S, Lionello M, Fasanaro E, Giacomelli L, Zanon S, Staffieri C, Dall'Igna F, Manzato E, Staffieri A (2013) Vestibular rehabilitation in elderly patients with central vestibular dysfunction: a prospective, randomized pilot study. AGE 35:2315-2327. https://doi.org/10.1007/s11357-012-94947

24. Matsui JI, Ryals BM, n.d. Hair cell regeneration: An exciting phenomenon.. . But will restoring hearing and balance be possible? Journal of Rehabilitation Research \& Development 42, 187

25. Meyers JR, Corwin JT (2008a) Morphological Correlates of Regeneration and Repair in the Inner Ear

26. Meyers JR, Corwin JT (2008b) Morphological Correlates of Regeneration and Repair in the Inner Ear. Springer, New York

27. Nicolas MT, Demêmes D, Martin A, Kupershmidt S, Barhanin J (2001) KCNQ1/KCNE1 potassium channel in mammalian vestibular dark cells. Hear Res 153:132-145

28. Palma S, Boldrini P, Nucci R, Fano RA, Cenacchi G, Martini A (2018) Melanin in human vestibular organs: what do we know now? An ultrastructural study and review of the literature. Hearing Balance Communication 16:101-107. https://doi.org/10.1080/21695717.2018.1461488

29. Pingault V, Ente D, Dastot-Le Moal F, Goossens M, Marlin S, Bondurand N (2010) Review and update of mutations causing Waardenburg syndrome. Hum Mutat 31:391-406. https://doi.org/10.1002/humu.21211

30. Pingault V, Faubert E, Baral V, Gherbi S, Loundon N, Couloigner V, Denoyelle F, Noël-Pétroff N, Le Pointe $D$, Elmaleh-Bergès $H$, Bondurand $M$, Marlin N, S (2015) SOX10 mutations mimic isolated hearing loss. Clin Genet 88:352-359. https://doi.org/10.1111/cge.12506

31. Pusch C, Hustert E, Pfeifer D, Südbeck P, Kist R, Roe B, Wang Z, Balling R, Blin N, Scherer G (1998) The SOX10 / Sox10 gene from human and mouse: sequence, expression, and transactivation by the encoded HMG domain transcription factor. Hum Genet 103:115-123. https://doi.org/10.1007/s004390050793

32. Sampaio ALL, Paine E, Schachern PA, Sutherland C, Cureoglu S, Olivieira CACP, Paparella MM, n.d. Histopathological morphometric study of cochleosaccular dysplasia in Dalmatian dogs $74,0-938$

33. Shi X, Wu N, Zhang Y, Guo W, Lin C, Yang S, n.d. Adeno-associated virus transformation into the normal miniature pig and the normal guinea pigs cochlea via scala tympani. Acta Oto Laryngologica 
34. Song J, Feng Y, Acke FR, Coucke P, Vleminckx K, Dhooge IJ (2016) Hearing loss in Waardenburg syndrome: a systematic review: Hearing loss in Waardenburg syndrome. Clin Genet 89:416-425. https://doi.org/10.1111/cge.12631

35. Strain GM (2015) The Genetics of Deafness in Domestic Animals. Frontiers in Veterinary Science 2. https://doi.org/10.3389/fvets.2015.00029

36. Straka H, Zwergal A, Cullen KE (2016) Vestibular animal models: contributions to understanding physiology and disease. J Neurol 263:10-23. https://doi.org/10.1007/s00415-015-7909-y

37. Sugiura A, Hilding DA, n.d. Cochleo-Saccular Degeneration in Hedlund White Mink. Acta Otolaryngologica $69,126-137$

38. Tribukait A, Rosenhall U, Österdahl B (2005) Morphological Characteristics of the Human Macula sacculi. Audiology Neurotology 10:90-96. https://doi.org/10.1159/000083364

39. Watanabe K, Takeda K, Katori Y, Ikeda K, Oshima T, Yasumoto K, Saito H, Takasaka T, Shibahara S (2000) Expression of the Sox10 gene during mouse inner ear development. Mol Brain Res 84:141145. https://doi.org/10.1016/S0169-328X(00)00236-9

40. Wiener-Vacher SR (2008) Vestibular disorders in children. International Journal of Audiology 47:578583. https://doi.org/10.1080/14992020802334358

41. Xu GY, Hao QQ, Zhong LL, Ren W, Yang SM (2016) SOX10 mutation is relevant to inner ear malformation in patients with Waardenburg syndrome. Zhonghua er bi yan hou tou jing wai ke za zhi $=$ Chinese. journal of otorhinolaryngology head neck surgery 51:832-837

42. Yang $\mathrm{T}-\mathrm{H}$, Young $\mathrm{Y}-\mathrm{H}$ (2005) Click-evoked myogenic potentials recorded on alert guinea pigs. Hear Res 205:277-283. https://doi.org/10.1016/j.heares.2005.03.029

43. Yi H, Guo W, Chen W, Chen L, Ye J, Yang S (2016) Miniature pigs: a large animal model of cochlear implantation 8, 5494-5502

44. Yi HJ, Guo W, Wu N, Li JN, Liu HZ, Ren LL, Liu PN, Yang SM, n.d. The temporal bone microdissection of miniature pigs as a useful large animal model for otologic research. Acta Oto Laryngologica 134, 26-33

45. Young Y-H (2018) Inner ear test battery in guinea pig models - a review. Acta Otolaryngol 138:519529. https://doi.org/10.1080/00016489.2017.1419576

46. Zhou X, Wang L, Du Y, Xie F, Li L, Liu Y, Liu C, Wang S, Zhang S, Huang X, Wang Y, Wei H (2016) Efficient Generation of Gene-Modified Pigs Harboring Precise Orthologous Human Mutation via CRISPR/Cas9-Induced Homology-Directed Repair in Zygotes: HUMAN MUTATION. Hum Mutat 37:110-118. https://doi.org/10.1002/humu.22913

\section{Tables}

Due to technical limitations, table 1 is only available as a download in the Supplemental Files section.

\section{Figures}


A

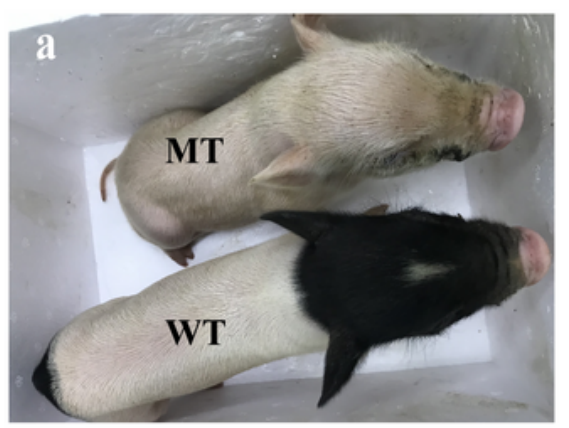

C
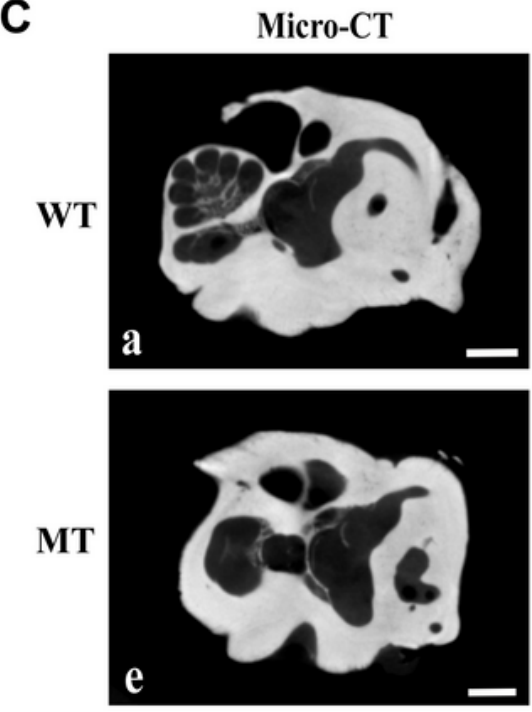
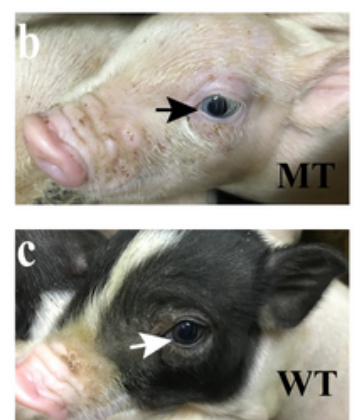

3D
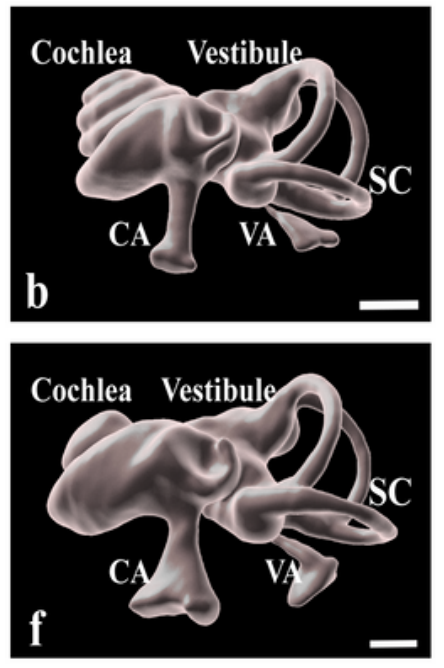

B

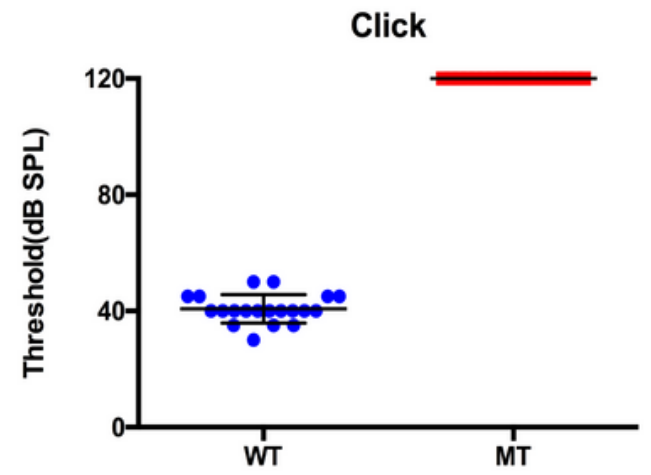

3D
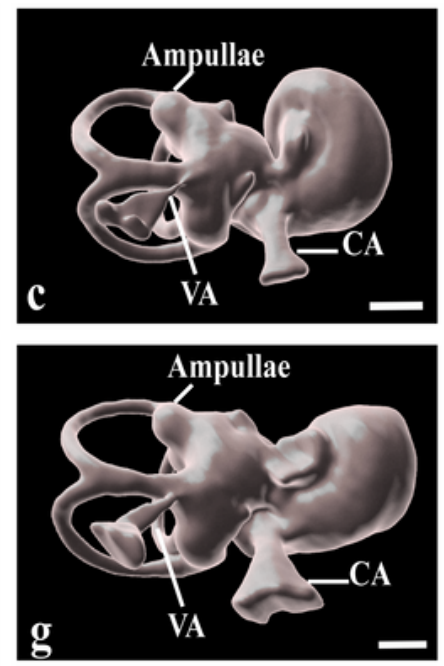
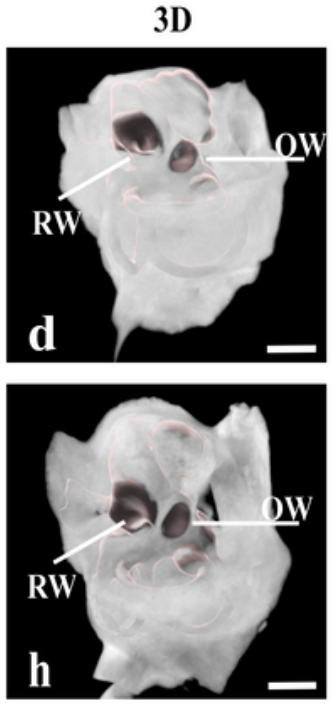

D
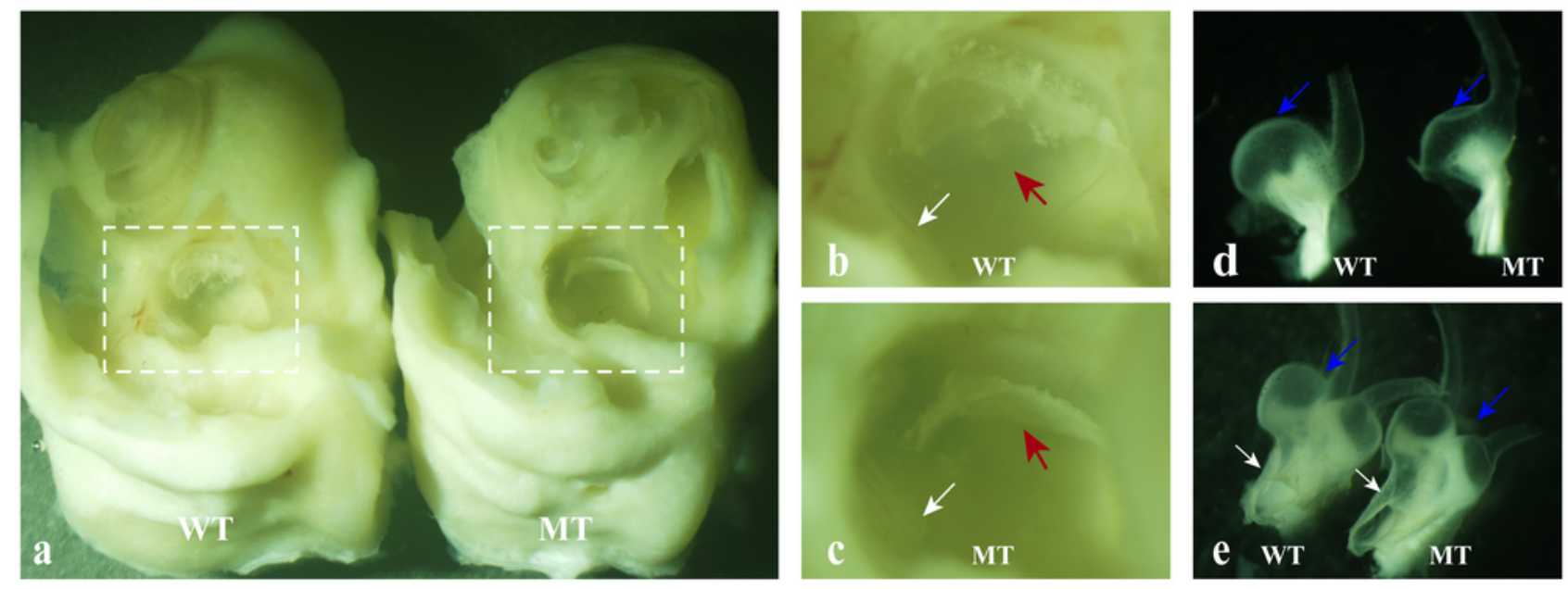

Figure 1

Profound sensorineural hearing loss and inner ear malformations in S0X10+/R109W miniature pigs. (A) Hypopigmentation of head, ears, hip (a) and retinal iris (b) in the mutant pigs. (B) Click results of wildtype and mutant pigs. The hearing threshold of wild-type individuals was $40.75 \pm 1.105 \mathrm{~dB}$ SPL ( $\mathrm{n}$ (ears) $=20$ ), whereas all mutants showed profound bilateral hearing loss, and remained irresponsive to stimulus intensities up to $120 \mathrm{~dB}$ SPL $(\mathrm{n}=20)$. (C) Micro-CT scanning results and 3-Dimensional 
reconstruction of the inner ear. Upper panel: the inner ear (left) in a wild-type miniature pig (a, b, c, d). Lower panel: the inner ear (left) in a mutant miniature pig (e, f, g, h). (CA, cochlear aqueduct; VA, vestibular aqueduct; SC, semicircular canal; RW, round window; OW, oval window. Scale bar: $2 \mathrm{~mm}$. (D) Views of vestibule in wild-type and mutant pig. The vestibular without covering periotic bone, showed vestibular cavity (a). Saccule (red arrow) and utricle (white arrow) of wild-type(b) and mutant miniature pig(c). Posterior semicircular canal of wild-type and mutant pig(d). Superior semicircular canal, lateral semicircular canal(blue arrow) and utricle (white arrow) of wild-type and mutant pig(e). (WT, wild-type; MT, mutation type).

A

WT
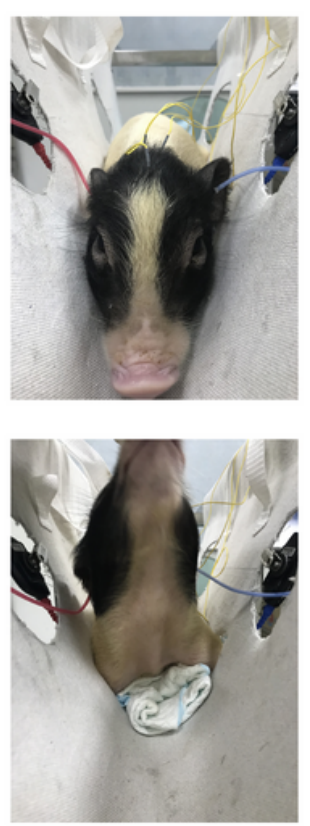

C

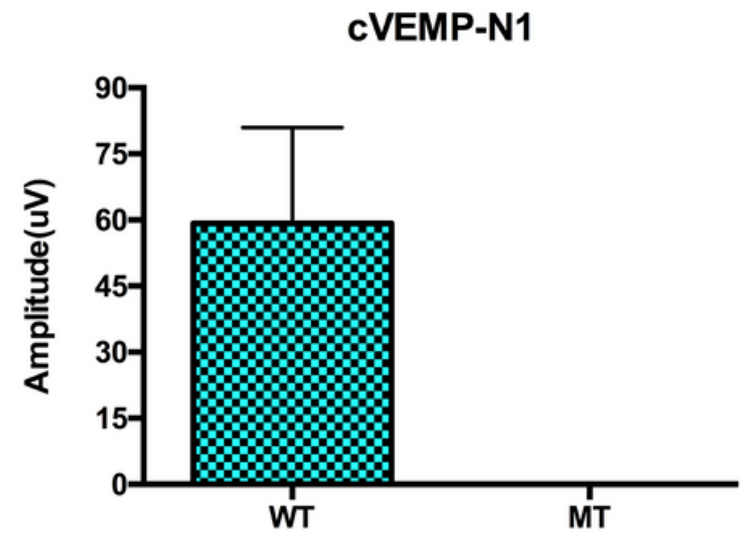

B
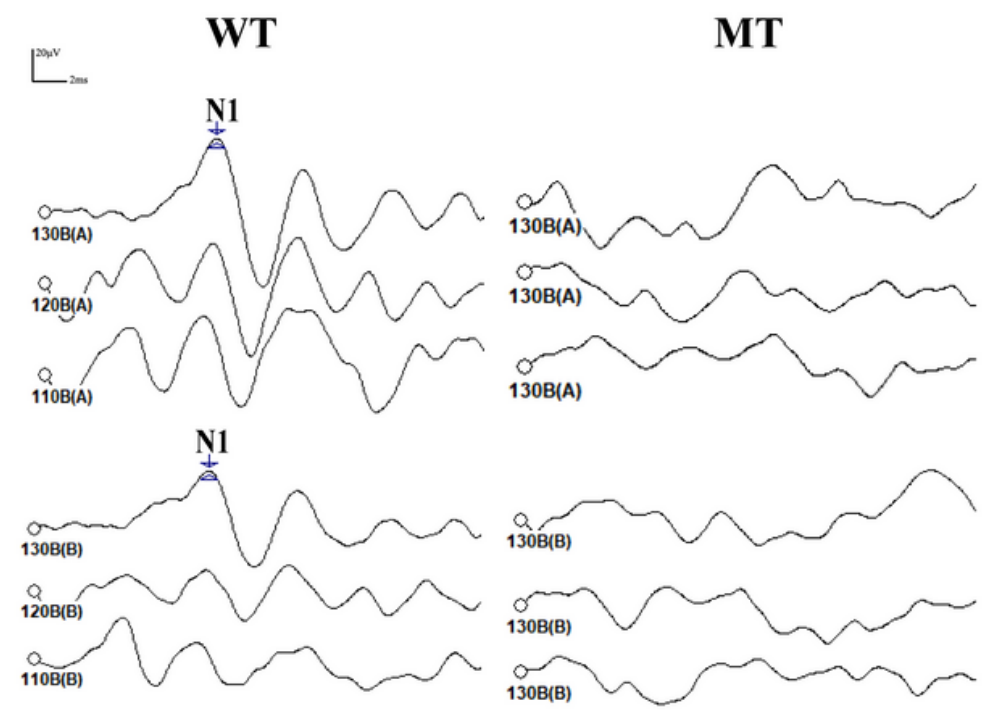

D

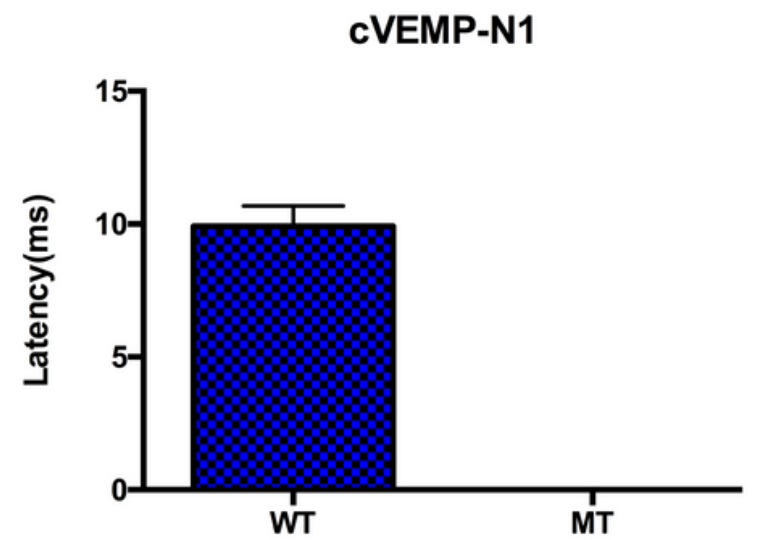

Figure 2

Impairments of cVEMP in SOX10+/R109W miniature pigs. (A) Illustration of cVEMP test recorded on alert wild-type ( $n$ (pigs) $=12$ ) and mutant pigs $(n=12)$. (B) The results of cVEMP test of wild-type and mutant pigs. cVEMP revealed peak(N1) of wild-type pigs (upper panel: right side; lower panel: left side), the 
response rate was $83 \%$ at stimulus intensity of $130 \mathrm{~dB}$ SPL, while no response was found on the mutant pigs.(C)(D) Graphs of cVEMP amplitudes and latencies in the wild-type $(\mathrm{n}($ ears $)=20)$ and the mutant pigs $(n=20)$.

A

SACCULE
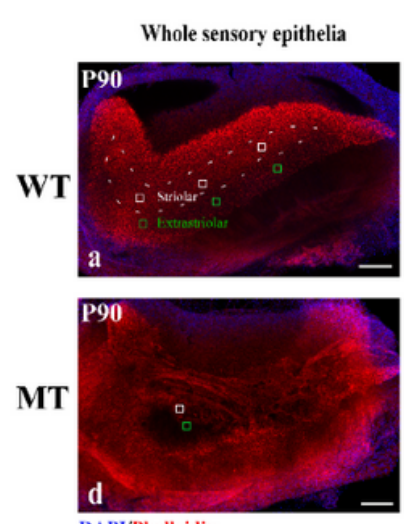

DAPL/Phalloidin
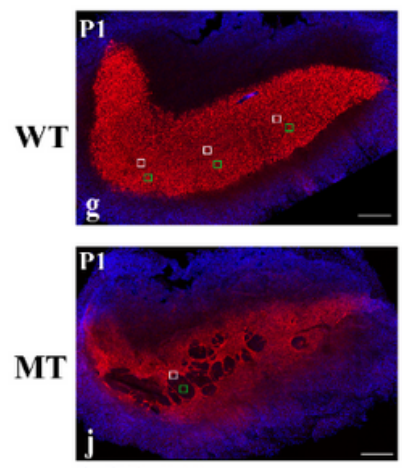

DAPI/Phalloidin
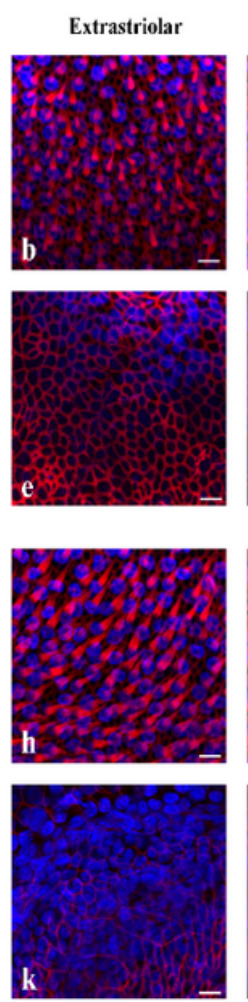
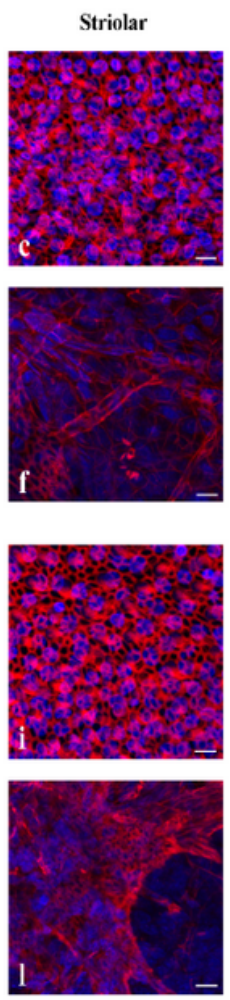

B

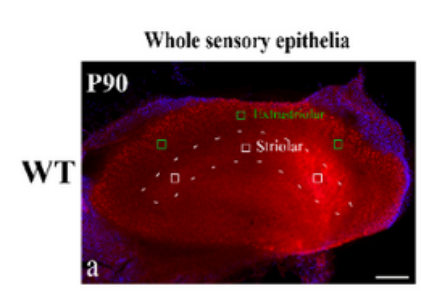

\section{UTRICLE}
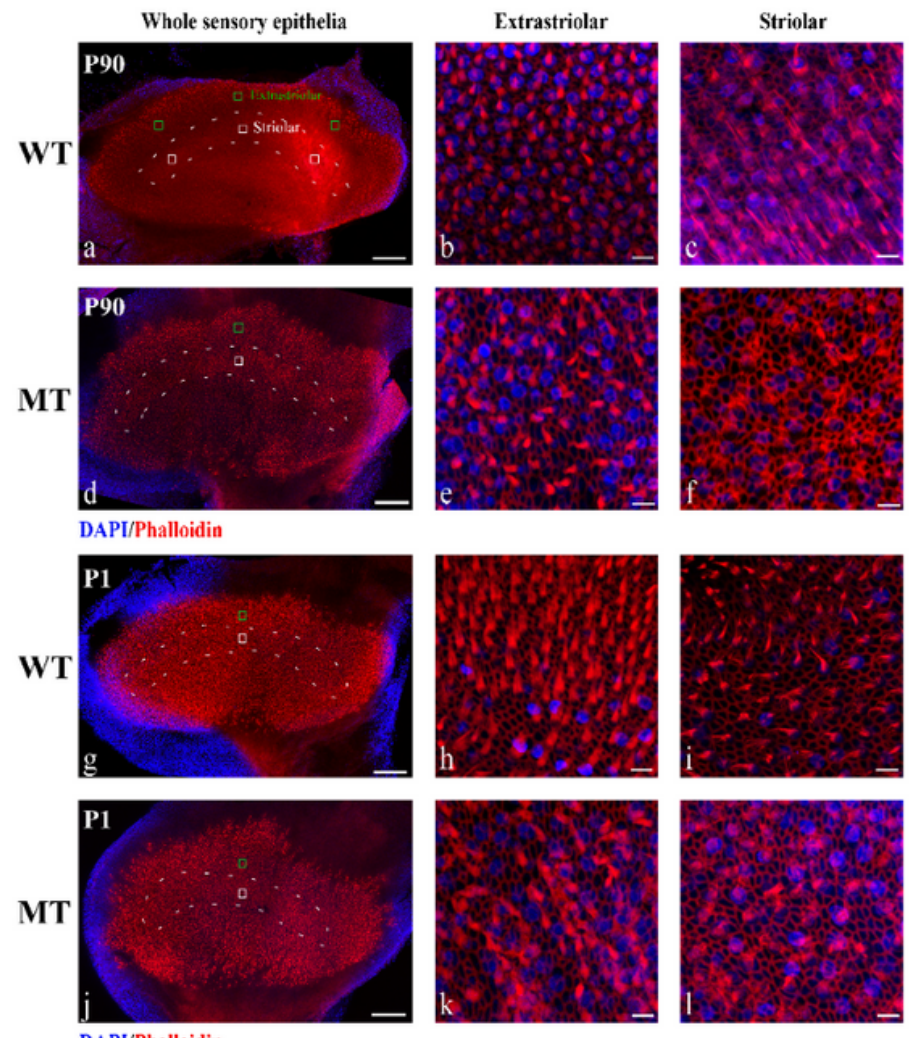

DAPI/Phalloidin

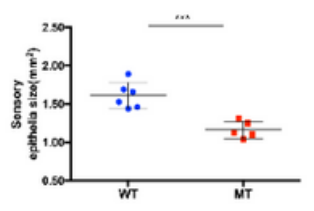

$\mathrm{m}$
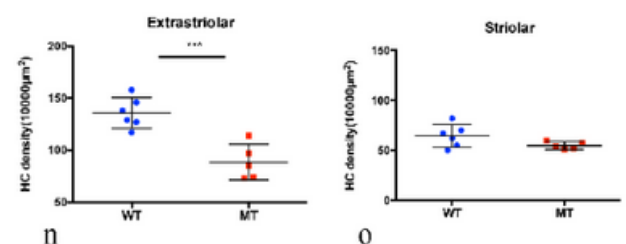

0

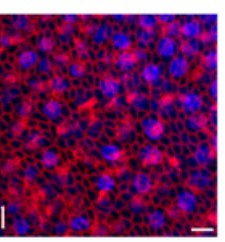

\section{Figure 3}

Vestibular hair cells loss in the saccule and utricle of S0X10+/R109W miniature pigs. (A) Vestibular hair cells loss in the saccule of SOX10+/R109W miniature pigs. (a)(d) Phalloidin immunofluorescence image showing the entire sensory epithelium of a saccule from wild-type (a) and mutant pigs (d) at postnatal 90 days. (b)(e) High magnification image of extrastriolar areas. (c)(f) High magnification image of striolar areas. (g)(j) Phalloidin immunofluorescence image showing the entire sensory epithelium of a saccule from wild-type (g) and mutant pigs(j) at postnatal 1 day. (h)(k) High magnification image of extrastriolar areas. (i)(I) High magnification image of striolar areas. Scale bar: a, d, g, j, $200 \mu \mathrm{m}$; b, c, e, f, h, i, k, l,10 10 m. (B) Utricular size and density of utricular hair cells in S0X10+/R109W miniature pigs. (a)(d) Phalloidin immunofluorescence image showing the entire sensory epithelium of an utricle from wild-type (a) and mutant pigs (d) at postnatal 90 days. (b)(e) High magnification image of extrastriolar areas. (c)(f) High magnification image of striolar areas. (g)(j) Phalloidin immunofluorescence image showing the entire 
sensory epithelium of an utricle from wild-type (g) and mutant pigs(j) at postnatal 1 day. (h)(k) High magnification image of extrastriolar areas. (i)(I) High magnification image of striolar areas. $(\mathrm{m})$ The size of utricle sensory epithelium in wild-type $(n=6)$ and mutant pigs $(n=5)$. (n) Density of utricular hair cells in extrastriolar area from wild-type $(n=6)$ and mutant pigs $(n=5)$. (o) Density of utricular hair cells in striolar area from wild-type( $(n=6)$ and mutant pigs $(n=5)$. Scale bar: a, d, g, j, $200 \mu m ; b, c, e, f, h, i, k, l, 10 \mu m$.

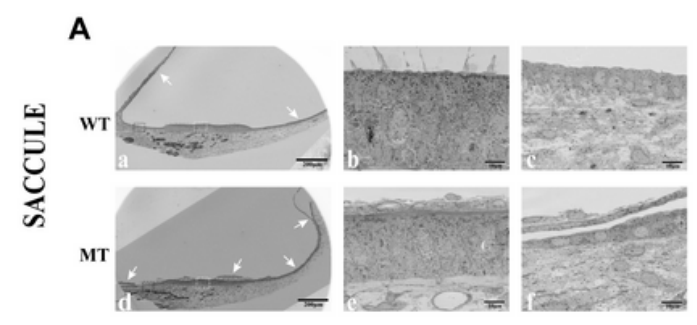

C
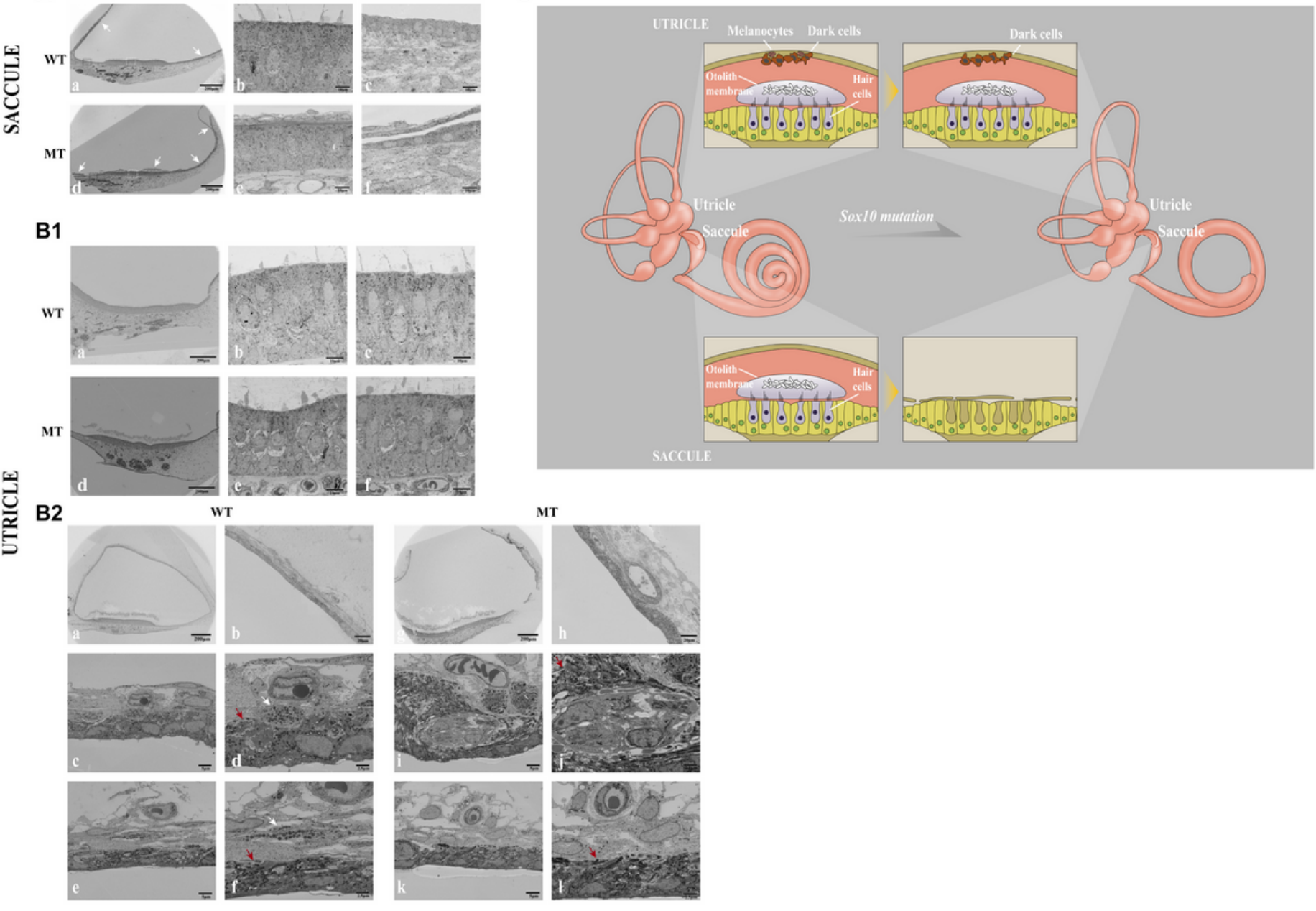

B1

Figure 4

Mutation in Sox10 caused developmental disorders of saccule and utricle. (A) Scanning electron micrographs of ultrathin sections of saccule in S0X10+/R109W miniature pigs at postnatal 1 day. (a)(d) SEM image of a cross-sectional view of the saccule in wild-type (a) and mutant pigs (d). High magnification image of the saccular sensory epithelium region from wild-type miniature pigs(b) and mutant pigs (e). High magnification image of the saccular roof epithelium from wild-type miniature pigs(c) and mutant pigs (f). The white arrow indicated the saccular roof epithelium. (B1) Scanning electron micrographs of ultrathin sections of utricle sensory epithelium in S0X10+/R109W miniature pigs at postnatal 1 day. (a)(d) SEM image of a cross-sectional view of the utricle sensory epithelium in wildtype (a) and mutant pigs (d). High magnification image of the utricle sensory epithelium region from wildtype miniature pigs $(b, c)$ and mutant pigs $(e, f)$. (B2) Scanning electron micrographs of ultrathin sections 
of utricle roof epithelium in SOX10+/R109W miniature pigs at postnatal 1 day. SEM image of a crosssectional view of the utricle roof epithelium in wild-type $(a, b)$ and mutant pigs $(g, h)$. High magnification image of the utricle roof epithelium region from wild-type miniature pigs $(c, d, e, f)$ and mutant pigs $(I, j, k, l)$. The white arrow indicated the melanocytes(MCs), the red arrow indicated the dark cells(DCs). (C) A schematic figure of saccule and utricle disorders in S0X10+/R109W miniature pigs. Saccule wall membrane collapsed and the hair cells in the mutant saccule shed off completely. Dark cells were disappeared in the mutant utricle.

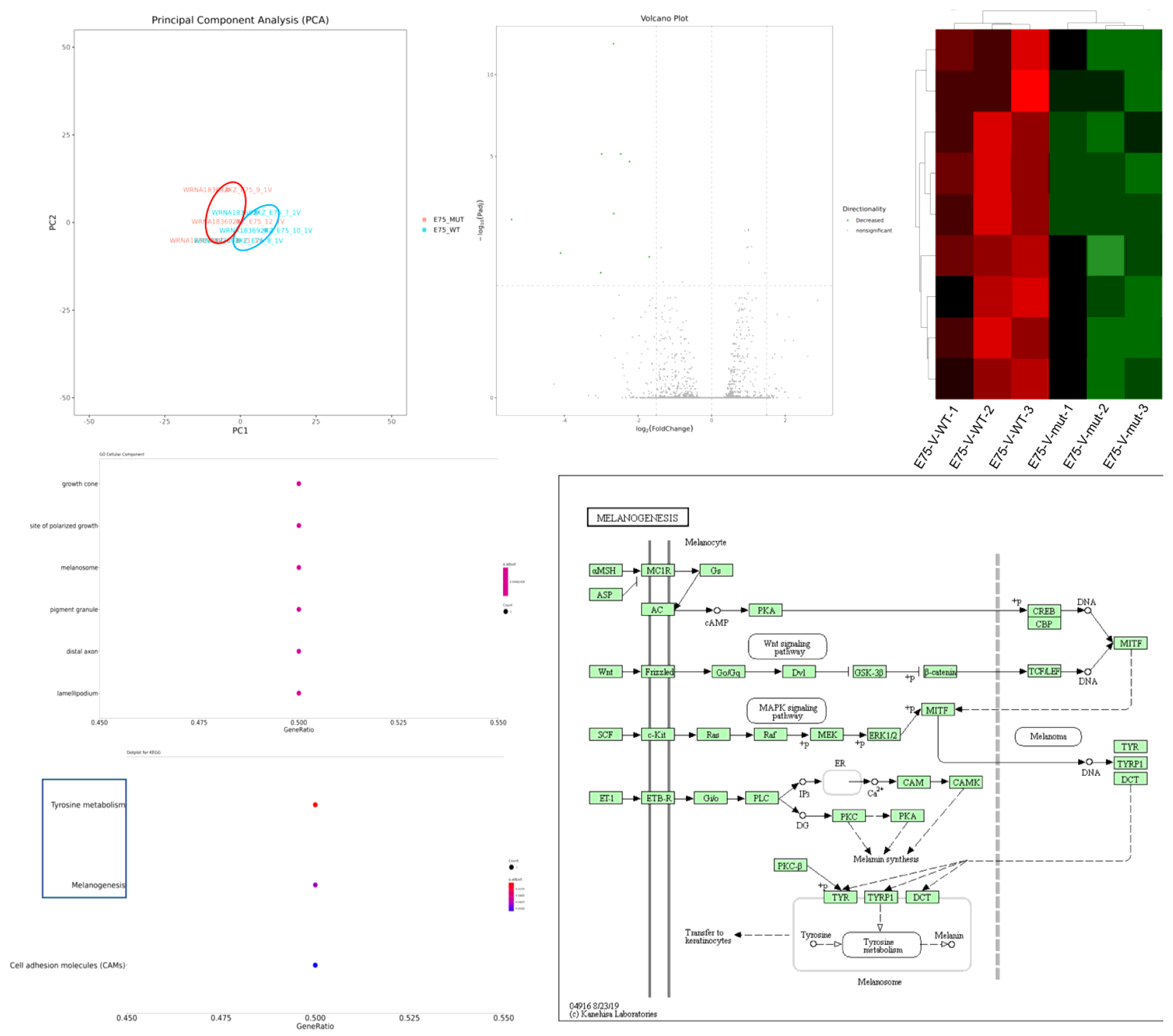

\section{Figure 5}

The profiling of transcriptome from wild-type and mutated vestibular. (A) The principal component analysis (PCA) of 3 paired vestibular samples from WT and Sox 10 mutated pigs respectively. Blue circle showing the WT-vestibular samples and samples from Sox10 mutated pigs were labeled by red circle. 
(B)Volcano map showing the different expression genes in Sox10 mutated vestibular compared with WT vestibular from E75 pigs. (C)Heatmap showing the different expression genes in Sox10 mutated vestibular compared with WT vestibular from E75 pigs. (D)GO analysis showing the enrichment molecular functions of Sox10 mutated vestibular related different expression genes. (E)KEGG analysis showing the enrichment signaling pathway of Sox 10 mutated vestibular related different expression genes. (F)A diagram of melanogenesis signaling pathway from KEGG showing DCT as a crucial factors regarding melanosome function and the survival of saccular and uticular hair cells.

A
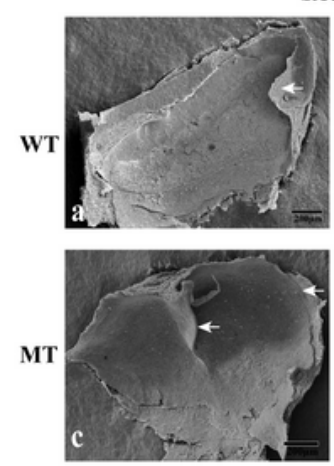

SACCULE
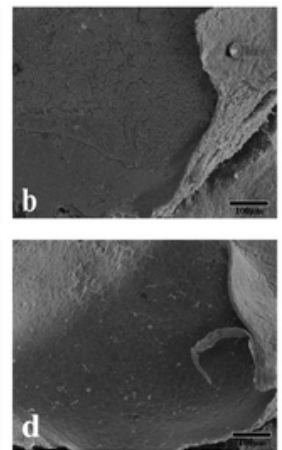
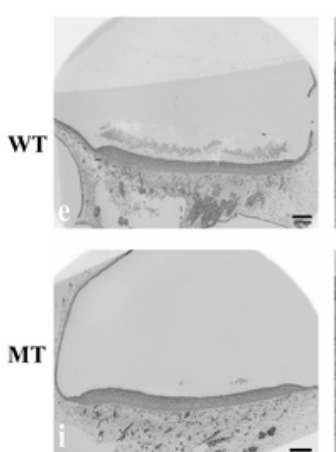

UTRICLE
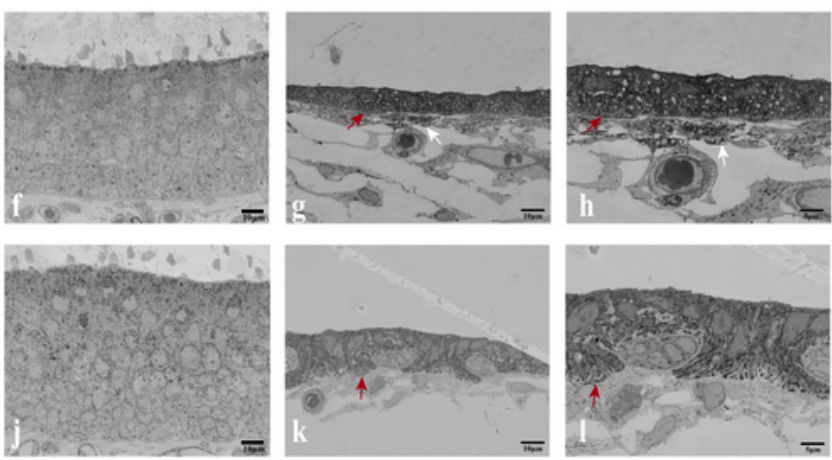

B
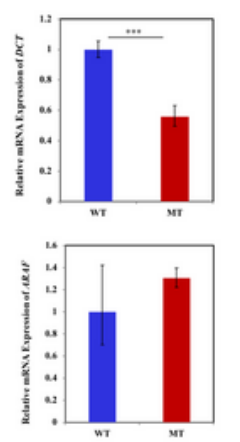
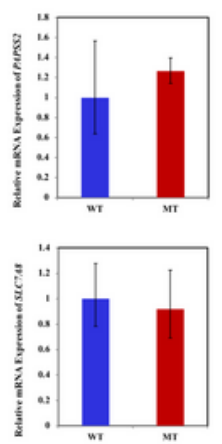
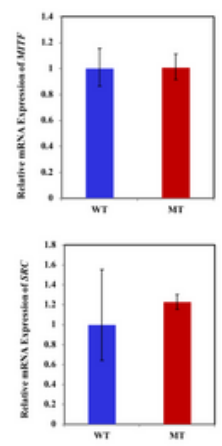

C a

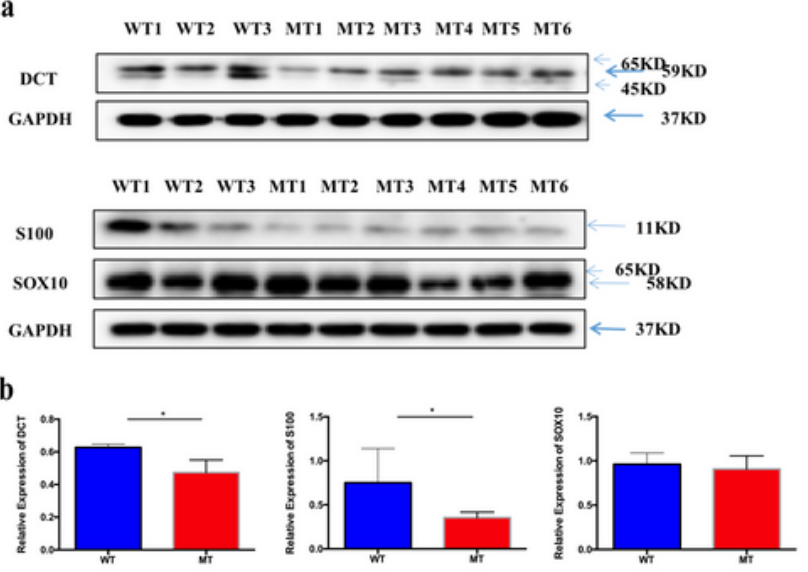

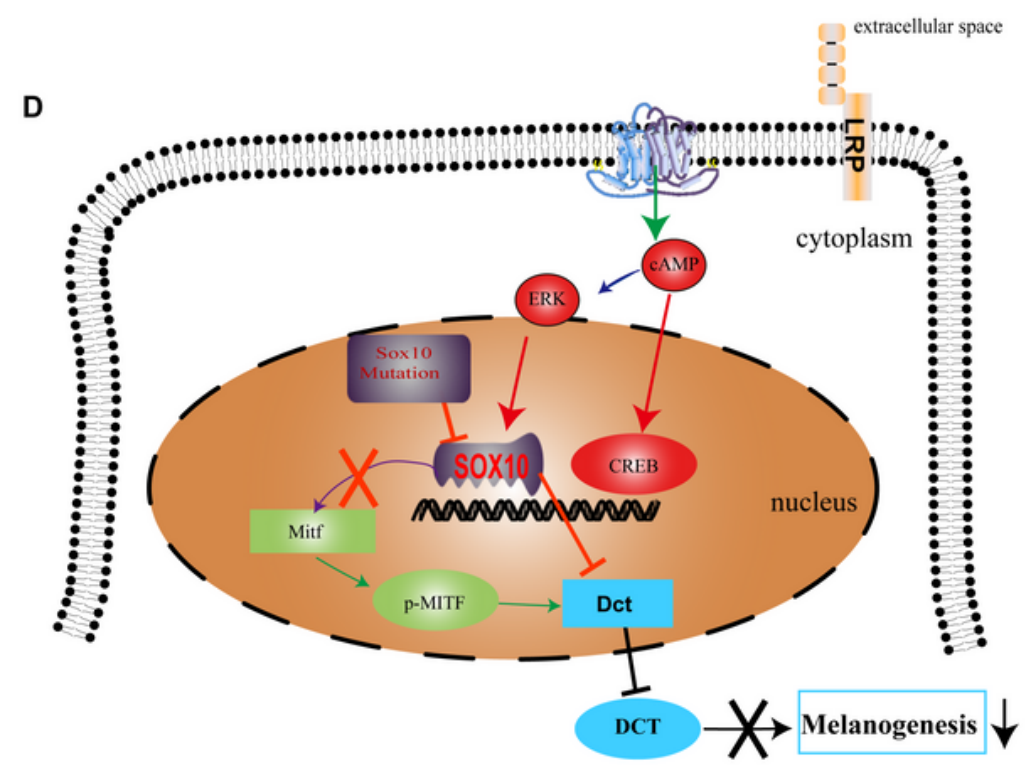




\section{Figure 6}

Sox10 mutation disrupts the KIT-DCT signaling pathway. (A) Mutation in Sox10 caused damage happened in the saccule and utricle at E75. (a-d) Scanning electron micrographs of saccule in SOX10+/R109W miniature pigs at E75. The white arrow indicated the saccular roof epithelium. (e-l) Scanning electron micrographs of ultrathin sections of utricle in SOX10+/R109W miniature pigs at E75. The white arrow indicated the melanocytes(MCs), the red arrow indicated the dark cells(DCs).

(B)Quantitative RT-PCR for Papss2, Araf, Src, Mitf, Slc7a8, Dct gene expression in vestibular end organ of wild-type and mutant pigs. (C)Western blot showing DCT, S100, S0X10 expression in vestibular end organ of wild-type and mutant pigs. (D)Model for SOX10-regulated KIT-DCT signaling pathway in vestibule morphogenesis. (The data are presented as mean \pm s.e.m. $n=3 ; * \llbracket p<0.05 \rrbracket \star \star \rrbracket p<0.01 ; * \star \star p<0.001$ ).

\section{Supplementary Files}

This is a list of supplementary files associated with this preprint. Click to download.

- Table1.pdf 